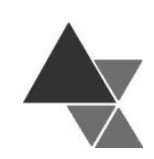

\title{
Potencializando o Desenvolvimento Humano Sustentável por meio do apoio a mercados locais em um município de Goiás, Brasil
}

\author{
Veruska Prado Alexandre ${ }^{1}$, Bruna Bittar Martins ${ }^{2}$ e Carlos Alexandre da Silva Harold ${ }^{3}$
}

Este estudo teve como objetivo potencializar a execução de mercados locais como estratégia para o desenvolvimento sustentável. Estudo de intervenção quali-quantitativo, conduzido entre fevereiro e dezembro de 2013 em um município de Goiás, Brasil. Participantes: gestor municipal da educação, um gestor do Programa Nacional de Alimentação Escolar (PNAE), um representante municipal da agricultura, nutricionistas, professores, agricultores familiares (AF). O projeto trabalhou três componentes: produção, cooperativismo e mercados. Por meio da integração entre diferentes setores e da atuação multiprofissional foi observado, no componente produção, a diversificação de cultivos, ampliação da variedade e quantidade de alimentos comercializados pela cooperativa, maior adequação dos alimentos processados às normas sanitárias e melhor organização produtiva. No componente "Cooperativismo", AF e gestores da cooperativa participaram de formações, levando ao aumento no número de cooperados e maior capacidade de gestão da cooperativa. Sobre o componente "mercados", os gestores do PNAE relataram como dificuldade a oferta irregular e insuficiente de alimentos. Os AF informaram ausência de apoio para produção e transporte. Conclui-se que os desafios quanto ao acesso de AF aos mercados locais podem ser melhor contornados por meio da cooperação intersetorial e da atuação interprofissional.

Palavras-chave: Desenvolvimento Humano Sustentável, mercados, políticas públicas, Segurança Alimentar e Nutricional.

\section{Empowering Sustainable Human Development by supporting local markets in a municipality of Goiás in Brazil}

The goal of this study was to empower the execution of local markets as a sustainable development strategy. This was a quali-quantitative intervention conducted between February and December 2013 in a municipality of Goiás - Brazil. Participants included a municipal education manager and National School Food Program (NSFP), a municipal agriculture representative, nutritionists, teachers, and family farmers (FF). The project addressed three components: production, cooperativism, and markets. Through the integration between different sectors and the multiprofessional cooperation was observed in the production component the diversification, increase the variety and quantity of food sold by the cooperative, better adaptation to sanitary regulations, and better productive organization. In the cooperative component, FFs and cooperative managers were trained, thus increasing the

${ }_{1}^{1}$ Professora da Faculdade de Nutrição. Universidade Federal de Goiás (UFG). Endereço para correspondência: Faculdade de Nutrição, Universidade Federal de Goiás. Rua 227, s/n, Quadra 68, Setor Leste Universitário. CEP 74.605-080. Tel.: (62) 3209-6270. E-mail: veruskaprado@ufg.br

${ }^{2}$ Nutricionista. Gestão e Elaboração de Projetos para a Agricultura Familiar (Gepaaf Assessoria Rural). E-mail: brunabm12@gmail.com

${ }^{3}$ Engenheiro Agrônomo. Empresa de Assistência Técnica e Extensão Rural (EMATER) do Paraná. E-mail: carlosharold.agro@gmail.com 
number of FF co-op members, motivating FFs, and engendering greater inter-professional performance by cooperative management. In the market component, NSFP managers reported that the problems in purchasing food from FFs was the irregular and insufficient supply. The FFs reported inadequate support for production and transportation. In conclusion, the challenges involved at local market access to FFs can be overcome through intersectoral and inter-professional cooperation.

Keywords: Sustainable Human Development, markets, public policies, Food and Nutrition Security.

\section{INTRODUÇÃO}

A promoção do desenvolvimento humano pleno deve orientar a atuação dos governos nas distintas nações. Recentemente com a publicação dos Objetivos do Desenvolvimento Sustentável pela Organização das Nações Unidas ${ }^{[1]}$, o termo sustentabilidade ganhou mais destaque neste debate.

Conceituar desenvolvimento humano sustentável é uma tarefa complexa, dada as inúmeras compreensões e significados associados aos termos "desenvolvimento" e "sustentável"[2]. Neste texto é compreendido a partir da constatação de que o pleno desenvolvimento humano tem maior potencial de ser alcançado quando adota modelos orientados pela intersecção entre as diferentes dimensões que determinam a vida humana, a saber, a social, a econômica, a cultural, a ambiental, considerando ainda a busca pela equidade.

Para Sen ${ }^{[3,4]}$ os seres humanos e o desenvolvimento de suas capacidades são considerados centrais no processo de desenvolvimento sustentável, sendo este orientado para o bem-estar e realização dos direitos humanos. O desenvolvimento sustentável, neste sentido, busca combinar o desenvolvimento econômico com a sustentabilidade ambiental e a inclusão social visando o pleno bem-estar humano[5].

Como parte do conjunto de elementos que potencializam o alcance do bem-estar humano, citamse a alimentação e o alimento e a centralidade que estes ocupam na vida social[ $[$. $\mathrm{O}$ ato de se alimentar, o acesso, a compra, o processamento e a venda dos alimentos estão inseridos em processos sociais e também estão integrados com outros determinantes do bem-estar, exigindo a promoção de ações intersetoriais para superação das formas de má nutrição e suas consequências ao desenvolvimento humano pleno e sustentável[7,8].

Medidas que promovam a disponibilidade de alimentos são fundamentais, mas não suficientes para melhorar os resultados nutricionais. É necessário atuar de forma abrangente sobre os sistemas alimentares assegurando o acesso a alimentos mais nutritivos, diversificados, vinculados à cultura e à produção local, assim como a capacidade de escolhas individuais para compor uma dieta saudável[ $[6,8]$.

Neste processo não apenas as atitudes dos consumidores individuais são importantes, como também os mercados locais, as políticas e programas públicos que em conjunto podem construir sistemas alimentares mais sustentáveis do ponto de vista ambiental, social, econômico e cultural. Conforme demonstrado no Brasil, nas últimas décadas, um conjunto de políticas públicas pode induzir ao desenvolvimento local por meio da diversificação das atividades econômicas e formas de viver ${ }^{[?]}$, pela superação das desigualdades ${ }^{[10]}$, por assegurar o acesso ao direito humano à alimentação e a Segurança Alimentar e Nutricional (SAN) ${ }^{[1,12,13,14]}$.

Dentre as políticas públicas de maior expressão no debate sobre desenvolvimento rural destacam-se os chamados mercados institucionais como o Programa Nacional de Alimentação Escolar (PNAE) e o Programa de Aquisição de Alimentos (PAA).

A mais recente Lei do PNAE, no 11.947/2009[15], determina a inclusão de AF, povos e comunidades tradicionais como fornecedores de alimentos para o Programa. Distintos desafios para o cumprimento desta execução têm sido citados como a multiplicidade de pontos de entrega dos alimentos exigida pela gestão do PNAE; a burocracia no processo 
de recebimento do pagamento por parte dos(as) AF; ausência de assessoramento técnico, a não realização do mapeamento da produção do município e região por parte da gestão do PNAE e dificuldade dos(as) AF em adequarem os alimentos processados às normas da Agência Nacional de Vigilância Sanitária (ANVISA), das agências estaduais de inspeção sanitária ou do Ministério da Agricultura, Pecuária e Abastecimento (MAPA), o que resulta na continuidade do chamado mercado informal de alimentos ${ }^{[16,17,18,19]}$.

Estes desafios podem gerar um menor interesse por parte dos(as) $\mathrm{AF}$ e suas organizações pelos mercados institucionais como meios de comercialização da produção. Estudo realizado em um território da cidadania em Goiás - Brasil encontrou como principais meios de comercialização da agricultura familiar as feiras locais, os atravessadores ou diretamente nas Centrais de abastecimento, sendo que poucos $\mathrm{AF}$ acessavam os mercados institucionais ${ }^{[20]}$.

As regiões e municípios onde a compra da agricultura familiar pelo PAA ou PNAE tem sido executada tem como característica a presença de AF organizados em associações ou cooperativas ${ }^{[20]}$, gestores públicos sensíveis ao cumprimento da legislação, nutricionistas comprometidas com a inclusão de alimentos da produção local e com os AF, merendeiras envolvidas no processo de compra de alimentos da agricultura familiar e, maior adequação do $\mathrm{n}^{\circ}$ de nutricionistas atuantes para a execução do PNAE conforme resolução[21] do Conselho Federal de Nutricionistas $(\mathrm{CFN})^{[19]}$.

Neste sentido, em resposta ao lançamento de um edital inserido no Programa de Extensão Universitária (ProExt), do Ministério da Educação (MEC)/Secretaria de Educação Superior (SESu), em 2013, a Faculdade de Nutrição (FANUT) e a Escola de Agronomia (EA) da Universidade Federal de Goiás (UFG), obtiveram aprovação e financiamento de um programa de extensão denominado "Construindo Novas Trajetórias e Fortalecendo Redes por Meio de Desenvolvimento Rural Sustentável".

Este programa foi desenvolvido em um município do interior de Goiás, inserido no Território da Cidadania do Vale Rio Vermelho, e buscava incentivar a diversificação da produção local de alimentos pelos AF e promover a comercialização destes nos mercados institucionais, PNAE e PAA, e locais, como as feiras ${ }^{[2] .}$ O programa de extensão tinha como enfoque o fortalecimento de uma cooperativa de agricultores enquanto estratégia de atuação intersetorial e sustentável[22], tendo como principal referencial desta ação sustentável a dimensão econômica.

O objetivo deste artigo é relatar o fortalecimento da rede de execução de mercados locais, por meio de comercialização via cooperativa, como estratégia de desenvolvimento humano sustentável.

\section{METODOLOGIA}

O estudo de intervenção foi desenvolvido entre fevereiro a dezembro de 2013, em parceria com uma cooperativa de agricultores de um município de pequeno porte populacional (35.371 habitantes), localizado a $92 \mathrm{~km}$ de Goiânia (capital de Goiás) e inserido no bioma Cerrado. Este município apresentava Índice de Desenvolvimento Humano (IDH) de 0,719 muito próximo da realidade brasileira que é de 0,727 (IBGE, 2014). Dentre os habitantes, 6.700 estão matriculados em alguma escola da rede, a qual é composta por 22 instituições de ensino municipais, estaduais e particulares ${ }^{[2]}$. O município contava com 675 Declarações de Aptidão ao Programa Nacional de Fortalecimento da Agricultura Familiar (DAP) ativas ${ }^{[24]}$.

A equipe de execução do projeto vinculada à UFG era composta por estudantes e professores pertencentes a diferentes cursos e áreas do conhecimento: nutrição, agronomia, medicina veterinária, engenharia florestal, engenharia de alimentos e comunicação social. No total 20 pessoas compuseram a equipe da UFG: 11 bolsistas e 05 voluntários de extensão; 01 nutricionista, 01 engenheiro agrônomo e 02 professores universitários (nutricionista e um agrônomo). $O$ nutricionista e engenheiro agrônomo contratados para a execução do projeto são aqui identificados como extensionistas rurais.

Participaram como comunidade externa à UFG: um gestor municipal da secretaria de educação, um interlocutor vinculado à gestão municipal para tratar de assuntos do setor da agricultura (o município não contava com uma secretaria da agricultura), um coordenador municipal do PNAE, três nutricionistas, seis professores (coordenadores de merenda escolar das escolas estaduais do município), 50 famílias de AF e membros da diretoria da cooperativa. 
Foram trabalhados, pela abordagem de rede, três componentes: cooperativismo, produção de alimentos e mercados. O componente "cooperativismo" teve como enfoque ações junto à cooperativa, voltadas para $\mathrm{o}$ incentivo ao cooperativismo. Neste caso foram levantadas as necessidades da cooperativa quanto a recursos humanos, físicos, financeiros $\mathrm{e}$ de apoio a comercialização. As ações planejadas buscavam aumentar o número de $\mathrm{AF} \operatorname{cooperados(as)~e~a~}$ participação destes(as) nas diversas ações da cooperativa.

Em relação ao componente "produção", o projeto contou com a participação de 50 famílias de $\mathrm{AF}$, vinculados a quatro assentamentos da reforma agrária $\mathrm{e}$ a uma comunidade rural. A escolha destas famílias foi realizada pela diretoria da cooperativa, tendo como principal critério o potencial de associação destas à cooperativa. Este potencial era classificado pela diretoria da cooperativa a partir de critérios subjetivos como: expressão de desejo de membros das famílias em participar da cooperativa, presença de produção (independente da escala) de alimentos in natura com potencial para os mercados locais. Estas famílias receberam assistência técnica com o objetivo de estimular e apoiar a produção diversificada de alimentos in natura e processados, adequados as exigências do PNAE/PAA. Exemplo de atividades desenvolvidas em parceria com os(as) AF: escalonamento da produção, orientações técnicas, análises de solos, formação sobre mercados institucionais e cooperativismo, rotulagem nutricional, orientações sobre uso (e redução) de agrotóxicos, etc.

O terceiro componente foi identificado como "mercados". Este componente tinha como enfoque os canais de comercialização: mercados institucionais (PNAE e PAA) e as feiras locais.

Estes componentes do projeto foram trabalhados simultaneamente durante 2013. Desta forma, mesmo desenvolvendo atividades com os (as) AF sobre produção de alimentos, temas e atividades associados aos componentes cooperativismo e mercados eram também tratados. Assim como quando a equipe atuava em parceria com profissionais envolvidos com a execução do PNAE, temas relacionados à produção de alimentos eram também abordados.
A equipe do projeto tinha como princípio de atuação o fortalecimento da cadeia de produção e consumo de alimentos no município, buscando construir uma rede de colaboração e apoio à cooperativa.

As diferentes ações desenvolvidas no âmbito destes três componentes do projeto foram pactuadas por um comitê gestor formado por membros da diretoria da cooperativa e equipe vinculada à UFG.

O projeto foi executado a partir de etapas: (1) pactuação dos objetivos e das ações com os dirigentes da cooperativa, (2) reconhecimento da realidade pela equipe da UFG em parceria com as familias de AF, direção da cooperativa e gestores municipais, (3) planejamento participativo, (4) implantação das ações e (5) avaliação.

A pactuação dos objetivos do projeto foi realizada no mês de fevereiro (mês 1), com representantes dos(as) AF cooperados, professores e estudantes da UFG e extensionistas rurais do projeto. Como resultados esperados com a execução da intervenção foram elencados:

- Fortalecimento da gestão da cooperativa, incluindo a reorganização da sede na zona urbana do município, aumento do volume de produtos comercializados e da renda da cooperativa.

- Ampliação do número de AF cooperados, tornando esta cooperativa uma entidade de agricultores familiares. Neste ponto consideramos pertinente destacar que ao início do projeto apenas quatro agricultores familiares eram cooperados e, destes, apenas um participava da gestão da cooperativa. Este resultado foi expresso pelos(as) AF e era compreendido como uma forma de tornar a cooperativa uma entidade $100 \%$ comprometida com a agricultura familiar.

- Oferta de Assistência Técnica e Extensão Rural (ATER) para 50 famílias de agricultores(as) familiares, sendo 45 destas assentadas da reforma agrária (quatro já integravam a cooperativa) e cinco famílias de agricultores familiares tradicionais (duas destas comercializavam produtos via cooperativa, mas não integravam o quadro de cooperados). 
- Ampliação do número e volume de produtos comercializados pela cooperativa para programas e políticas governamentais.

- Efetivação de negociação de compra/venda com o PNAE via cooperativa.

- Inserção de alimentos da cooperativa na alimentação ofertada nas escolas estaduais.

- Construção e implantação de um projeto de venda do PAA, na modalidade compra com doação simultânea.

- Ampliação da quantidade e variedade de alimentos comercializados pela cooperativa nas feiras locais.

- Aumento do número de agricultores participantes da feira municipal do produtor rural e abertura de nova feira local.

- Apoio à regularização sanitária dos alimentos processados produzidos.

Esta citação não indica nenhuma ordem de prioridade, pelo contrário estes objetivos foram buscados de forma simultânea dado o curto período de tempo para a execução do projeto (11 meses). As etapas de reconhecimento da realidade e planejamento das ações foram realizadas nos meses de fevereiro (mês 1) e março (mês 2) e revisadas sempre que necessário. Para fins de melhor organização os extensionistas rurais se dividiram, no primeiro momento, em duas frentes:

- Engenheiro agrônomo: dedicou-se a organizar as ações de ATER, realizar mapeamento da feira do produtor rural e realizar diagnóstico sobre recursos físicos, financeiros e organização da cooperativa.

- Nutricionista: buscou conhecer a execução do PNAE no município, a presença de órgãos de controle e fiscalização sanitária (Vigilância sanitária municipal, sistema de inspeção municipal) e mapear entidades que atendiam pessoas em Insegurança Alimentar e Nutricional (INSAN), visando definir as instituições potencialmente recebedoras de alimentos do PAA.

Nesta etapa os extensionistas também identificaram potenciais parceiros locais para apoio às ações do projeto e da cooperativa.
Ainda no segundo mês de execução do projeto (março/2013), as ações voltadas para o componente "Produção de alimentos" foram iniciadas, envolvendo a equipe de estudantes. A etapa de reconhecimento da realidade e planejamento das ações nas propriedades rurais foi realizada por uma dupla, sempre que possível, formada por um estudante vinculado à área das agrárias e um vinculado a ciências dos alimentos.

Por meio de entrevistas semiestruturadas e rodas de conversa foram levantadas informações quanto à produção de alimentos, o conhecimento sobre mercados institucionais, visão sobre a cooperativa e aspectos de saúde das famílias. Posteriormente este levantamento orientou a estruturação de planos de ações para cada propriedade e também de ações comunitárias, como dias de campo da saúde e de técnicas de plantio e manejo de cultivos. As ações planejadas foram executadas nos meses seguintes, de março (mês 2) a dezembro/2013 (mês 11).

A avaliação do projeto foi realizada de forma constante a partir de um delineamento do tipo multimétodos, associada a cooperação e participação das partes interessadas, favorecendo a utilização dos resultados para o fortalecimento e revisão das

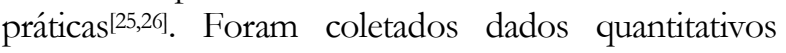
quando do início e ao final da intervenção, sendo estes posteriormente tabulados em Excel 2010 e expressos em frequência absoluta. Adicionalmente foi realizada análise do discurso ${ }^{[2]}$ dos diários de campo e anotações gerais da equipe da UFG envolvida na execução do projeto.

\section{RESULTADOS E DISCUSSÃO}

A construção de um conjunto de ações voltadas para o desenvolvimento humano sustentável, por meio do desenvolvimento rural e oferta de alimentos saudáveis nas escolas foi concebida a partir da execução de ações vinculadas a três componentes: cooperativismo, produção de alimentos e mercados.

Buscando melhor orientar o trabalho da equipe envolvida estabeleceu-se um marco conceitual o qual identificava a cooperativa de agricultores como o elo entre os processos de produção e o consumo de alimentos, representado aqui pelos mercados. Da mesma forma os mercados locais foram considerados 
como elementos primordiais para o desenvolvimento rural e sustentabilidade das ações.

O projeto tinha como enfoque o fortalecimento destes componentes, buscando aumentar o número de $\mathrm{AF}$ cooperados e que a cooperativa passasse a atuar como um elemento promotor do desenvolvimento local sustentável. O fortalecimento das cooperativas e outras formas de organização dos agricultores a partir da atuação sobre os mercados locais é também relatada por outros autores ${ }^{[10,28] \text {. }}$

As palavras "desenvolvimento", "sustentável", "rural" e "urbano" são passíveis de problematização quanto aos seus significados, no entanto, a exceção do termo "sustentabilidade" os demais não serão objetos de debate neste artigo. Para fins desta ação a sustentabilidade apresenta uma polissemia de significados, estando relacionada ao sentido de continuidade das ações desenvolvidas após, por exemplo, a troca de lideranças, também a ideia de resistência, manutenção ou institucionalização de uma forma de agir sobre a realidade, também tem relação com os aspectos ambientais onde o desenvolvimento de uma comunidade deve respeitar o meio ambiente e preservá-lo para as futuras gerações; ou ainda no sentido de manutenção de acesso a recursos fundamentais para a continuidade de uma ação[29].

Especificamente quanto aos mercados institucionais vinculados a política de SAN, como é o caso do PAA e PNAE, a sustentabilidade também assume uma dimensão de oferta permanente de alimentos em quantidade e qualidade adequadas.

Distintos aspectos podem interferir neste processo, como a ausência de uma política agrícola e agrária adequada às demandas do município, o que se expressa muitas vezes na ausência de ações da gestão municipal voltadas para à agricultura familiar, na precarização do trabalho dos(as) extensionistas rurais ou na ausência de oferta de ATER, o incipiente acesso às políticas de crédito rural voltadas para a agricultura familiar e, também, o descumprimento do processo de regularização sanitária de empreendimentos da agricultura familiar e da economia solidária[19].

A atuação deste projeto em parceria com a cooperativa local foi também uma forma de dar sustentabilidade as ações já desenvolvidas pela UFG no município. A EA-UFG desenvolvia ações de ensino, pesquisa e extensão junto a assentados da reforma agrária no município e a FANUT-UFG desenvolveu atividades de formação e apoio à execução do PNAE na Secretaria Municipal de Educação (SME) e no conselho de alimentação escolar (CAE).

Cabe ainda destacar que as atuações da UFG no território deste município eram setorializadas e fragmentadas entre a produção e consumo de alimentos. A fragmentação do sistema alimentar entre produção e consumo é percebida tanto no cotidiano das pessoas como também nas abordagens teóricas ${ }^{[0]}$, sendo consequência e também causa da compreensão que separa políticas econômicas, das sociais.

Desta forma, a parceria com esta cooperativa foi planejada, dando origem a uma proposta de um programa de extensão que atuasse de forma intersetorial e interprofissional na promoção do desenvolvimento rural sustentável por meio do fortalecimento de mercados locais.

Em relação a realidade produtiva foram identificados no início do projeto 24 itens em produção, sendo 16 alimentos in natura, três minimamente processados (mandioca descascada, farinha de mandioca e polvilho) e cinco alimentos processados (bolo, biscoito de polvilho, rosca/pão doce, geleias, doces).

O potencial de produção foi identificado por meio dos indicadores "disponibilidade de áreas de cultivo" e "relato de cultivo anterior". Sobre este último as famílias de AF relataram cultivo anterior de: abacate, abacaxi, abóbora japonesa, beterraba, cajá-manga, cebola de folha, cenoura, chuchu, feijão, manga, ovo caipira, pão de milho e repolho. Destes alimentos, seis passaram a compor a comercialização da cooperativa em 2013: abóbora japonesa, beterraba, cebola de folha, cenoura, ovos e repolho.

Em paralelo a esta etapa as duplas de estudantes, os extensionistas e as familias realizaram o planejamento das ações e iniciaram a implantação destas a partir de visitas quinzenais entre os meses $2 \mathrm{e}$ 11 do projeto (março a dezembro de 2013). As ações de ATER eram voltadas para todos os membros da família e realizadas por meio de metodologias participativas e 
problematizadoras considerando a realidade encontrada na propriedade, os aspectos físicos (geografia e acesso a água, por exemplo), ou ainda a composição familiar, as questões de saúde e de renda.

Dentre as atividades desenvolvidas citam-se: escalonamento da produção, realização de orientações técnicas gerais sobre plantio e cuidado no campo, análises de solos, formação sobre mercados institucionais e cooperativismo, formação sobre boas práticas na fabricação e manipulação de alimentos, normas sanitárias, orientações sobre manejo de culturas, etc. Também foram desenvolvidas ações de promoção e educação em saúde juntamente com os AF por meio de "dias de campo da saúde".

No caso da produção, esta era voltada para ampliar a oferta de alimentos in natura e processados aos mercados institucionais, feiras locais e também enfocavam a melhoria na alimentação da família. Os alimentos in natura são os que não sofrem qualquer tipo de alteração após colhidos, salvo lavagem simples ${ }^{[30,31]}$.

Os alimentos minimamente processados referem-se aqueles que são submetidos a algum processo de corte, secagem, moagem, fermentação, pasteurização, refrigeração ou congelamento, porém sem nenhuma adição de sal, açúcar, óleos, gorduras ou outras substâncias[30,31].

Já os alimentos processados apresentam adição de algum componente/ingrediente ausente de sua composição original, dando origem a, por exemplo, compotas, queijos, bolos, pães, etc. ${ }^{[30,31]}$. No caso destes últimos, as ações do projeto buscavam reduzir a quantidade de açúcar, sal e gordura utilizados no processamento, tornando-os adequados sob o ponto de vista da alimentação saudável[30].

No tocante ao PAA o planejamento e execução das ações do componente "produção" foi orientado pelas demandas por alimentos identificadas junto a instituições com potencial de receber alimentos e negociadas com os AF, determinando a diversidade de cultivos e a quantidade de alimentos que comporiam o projeto de venda do PAA na modalidade compra com doação simultânea.

Em relação às ações desenvolvidas junto à cooperativa destacam-se a eleição de nova diretoria, sendo esta realizada em conformidade com a lei do cooperativismo e possibilitando a regularização da documentação da entidade. Realização de rodas de conversa com os associados e com famílias de AF não cooperadas tratando de temas como cooperativismo, planejamento rural, mercados institucionais, etc. Apoio à realização de reuniões/assembleias periódicas, sendo que esta ação foi relatada como fundamental para melhor compreender as ações desenvolvidas pela cooperativa e a consolidação de um sentimento de pertencimento pelos(as) AF a esta. Realização de inventário de recursos financeiros e físicos da cooperativa. Organização da nova sede.

Estas ações em conjunto com as realizadas nos demais componentes do projeto foram citadas como aspectos que levaram ao aumento no número de $\mathrm{AF}$ cooperados de 6, no início, para 58 ao final do projeto (Quadro 1) e relato de maior motivação em participar da cooperativa por parte dos(as) AF.

No componente mercado, a equipe do projeto buscou ampliar o acesso a mercados institucionais uma vez que $\mathrm{AF}$ vinculados à cooperativa forneciam soja para o programa do biodiesel. Foram trabalhados três canais de comercialização: feira local, PNAE e PAA. No caso da feira local, a cooperativa optou por fortalecer a participação de seus cooperados na feira do produtor rural, realizada pela prefeitura na zona urbana do município uma vez por semana, e abrir uma nova feira em uma região da cidade que não era contemplada por este canal de comercialização.

A equipe trabalhou na construção do primeiro projeto de PAA da cooperativa, na modalidade "Compra com doação simultânea", tendo conseguido assinar e iniciar as entregas ainda dentro do ano de 2013 (Quadro 1).

Quanto ao PNAE, o planejamento foi voltado para fechar um projeto de venda com a SME via cooperativa e promover a compra de alimentos da AF pelas escolas estaduais e SME de municípios circunvizinhos. No início do projeto a cooperativa não havia acessado o PNAE, as vendas eram realizadas por meio de contratos individuais entre AF (cooperados) e a SME.

No município estudado foram encontrados dois tipos de gestão do PNAE. A Secretaria Estadual de 
Educação (Seduc) adota a gestão escolarizada, ou seja, reencaminha o dinheiro enviado pelo FNDE para as escolas, passando estas a serem as unidades executoras do programa, assumindo a responsabilidade pelos processos de aquisição dos alimentos, como o lançamento da chamada pública.

A SME adota a chamada gestão centralizada, na qual o recurso é todo gerenciado e gasto pela própria secretaria por meio do setor de compras e um departamento de alimentação escolar [32].

Estes diferentes tipos de gestão do PNAE levam também a divergentes formas de execução de alguns passos do processo de compra da agricultura familiar pela alimentação escolar [33]. Por exemplo, na gestão escolarizada presente nas escolas estaduais os cardápios eram elaborados por coordenadores especiais de merenda escolar (professores) a partir de fichas de preparações (receitas) enviadas pelos nutricionistas da Gerência Estadual de Merenda Escolar (Gemes)/Seduc.

O acompanhamento deste cardápio era predominantemente realizado por meio de supervisores da Gemes, os quais são professores com distintas formações. Desta forma, cabia ao coordenador da merenda da escola estadual estar envolvido com o mapeamento dos alimentos locais para então adequar a utilização das fichas de preparações à realidade local[33]. Já nas escolas vinculadas à SME, o nutricionista do município realizava o mapeamento da produção, elaborava o cardápio e avaliava periodicamente a sua realização diretamente nas escolas.

Outra importante diferença nestes arranjos de gestão do PNAE pode ser observada no caso das chamadas públicas. Na SME estas são publicadas e direcionadas a atender a todas as escolas do município. Já na realidade das unidades escolares estaduais, cada escola deveria publicar a sua chamada publicada.

A equipe do projeto buscou apoiar as(os) coordenadoras(es) de merenda escolar da Seduc neste processo, adequando o volume de pedidos, prazos/datas e rotas de entrega, etc. Alexandre, Pereira e Medina ${ }^{[33]}$ apontam como estratégia para aumentar a compra de alimentos da agricultura familiar pelas escolas com gestão escolarizada, a publicação e organização de chamadas públicas de forma coordenada contemplando, por exemplo, períodos semelhantes para entrega.

resultados:

Sobre os mercados cabe ressaltar como

- Feiras: a dificuldade em manter a oferta de alimentos escalonada, variada e em quantidade adequada, impossibilitou a continuidade da feira aberta pela cooperativa. Assim como no início do projeto, ao final dos 11 meses de execução os cooperados participavam apenas da feira do produtor rural organizada pela prefeitura. Este resultado pode também ser interpretado como um indicador negativo de sustentabilidade, do ponto de vista da renda.

- Ao final foi observada uma ampliação da diversidade alimentos comercializados pelos agricultores familiares cooperados nos diferentes mercados e, também, dos produtos comercializados pela própria cooperativa para programas e políticas governamentais. No início do projeto $\mathrm{AF}$ vinculados à cooperativa comercializavam seis produtos: soja para o programa Biodiesel e, para o PNAE: alface, banana prata, couve, mandioca descascada e biscoito de polvilho. Ao final a cooperativa comercializava 35 alimentos sendo 24 in natura e 11 processados, acessando 3 mercados institucionais: Biodiesel, PAA e PNAE.

- Em relação ao PNAE e PAA os diferentes atores envolvidos relataram potencialidades e dificuldades destes.

No início do projeto os responsáveis pela execução do PNAE relataram como a principal dificuldade para a compra de alimentos da agricultura familiar a oferta irregular e em quantidade aquém da demanda.

Os(as) AF relataram ausência de apoio para produção e transporte. Este diagnóstico orientou as ações do projeto e resultaram em redução considerável da frequência destes tipos de falas ao final da intervenção. A oferta de ATER às famílias de AF e o estabelecimento de rotas e parceiros para o transporte dos alimentos, contribuiu para que ao final do projeto estes pontos já não representassem aspectos críticos para os(as) agricultores(as) cooperados(as). Um dos resultados mais expressivos do projeto foi a ampliação do número de alimentos produzidos pelos $\mathrm{AF}$ e, 
posteriormente, comercializados via cooperativa com o PNAE (Quadro 1).

No tocante às normas sanitárias, ao final do projeto os AF associavam estas como um fator limitante ao acesso ao PNAE. Em referência ao PAA relataram maior atratividade pelo programa em decorrência deste, quando da execução do projeto, apresentar normatização para a compra menos burocrática do que o PNAE. Na ocasião o PAA aceitava declarações da vigilância sanitária municipal atestando a qualidade higiênico-sanitária dos alimentos. A fala de um agricultor ilustra parte desta afirmação:

'PNAE não é igual ao PAA não! No PNAE eles compra, vai exigir a vigilância. Já o PAA é doação. Tem que ter qualidade também mas é diferente... uma coisa é PNAE, outra é PAA." (Agricultor familiar).

A ampliação da variedade de produtos ofertados pela cooperativa foi um dos resultados mais expressivos do projeto, levando à ampliação da oferta para o PNAE e à execução de um projeto do PAA. No âmbito da comercialização do PAA foi fechado o compromisso de entrega de 29 produtos entre frutas, legumes, verduras, carnes, ovos e alimentos processados (Quadro 1).

A variedade de produtos cultivados pelos $\mathrm{AF}$ é um elemento extremamente utilizado como caracterizador desta categoria sociopolítica e valorizado por garantir o acesso a uma alimentação adequada e saudável[34,35,36,37].

No entanto, os desafios presentes no cotidiano do trabalho na propriedade rural, associado à necessidade de construir habilidades de comercialização, podem ser elementos que influenciam na percepção do AF quanto a necessidade de tornar a produção mais especializada por propriedade, reduzindo o número de produtos cultivados $\mathrm{e}$ associados ao produtor(a):

"PAA foi importante, vai ser importante pra gente manter este pique, estes seis mil e pouco dele ajuda o 'caboco'. Mas no próximo tem que diminuir o número de produtos para plantar. Seis ou sete produtos é muito para um produtor cuidar. No próximo vamos orientar direto 1 ou 2 produtos, vai ser melhor." (membro da diretoria da cooperativa, agricultor familiar).

Um agricultor até qualificou melhor esta questão, afirmando que o desafio está no processo de comercialização e entrega dos alimentos:

"O desafio é como comercializar e entregar. Produzir a gente consegue". (agricultor familiar participante do PAA).

- Ampliação do acesso das mulheres, agricultoras familiares, de forma oficial aos mercados institucionais. Ao final do projeto 16 agricultoras familiares participaram, identificadas formalmente pelo cadastro de pessoa física, no projeto de venda do PAA (Quadro $1)$.

- Realização de atividades com profissionais da SME: formação e sensibilização para inclusão de alimentos locais na alimentação escolar ofertada nas escolas municipais, aproximação entre AF e nutricionistas do PNAE, curso de elaboração de chamadas públicas conforme a lei 11.947/2009[15].

- Em termos de promoção da alimentação saudável, pode ser observado uma melhora na qualidade da alimentação ofertada para os estudantes. Uma das medidas de avaliação deste projeto foi realizada em 2014, por meio de análise de cardápios dos anos de 2012 e 2013, portanto, antes e durante a execução do projeto. Esta pesquisa analisou cardápios de três escolas municipais e observou redução na oferta de preparações com açúcar adicionado em 2013; maior frequência de carnes, ovos e frutas in natura e a baixa disponibilidade de cereais matinais, biscoitos e bolos de uso restrito pela legislação do PNAE[38].

Uma síntese do conjunto de resultados obtidos pelo projeto pode ser observada no Quadro 1. 
Quadro 1. Síntese quali-quantitativa dos resultados do projeto. Goiânia, 2016

\begin{tabular}{|c|c|c|}
\hline DESCRIÇÃO & 2012 & DEZEMBRO DE 2013 \\
\hline \multicolumn{3}{|c|}{ PNAE } \\
\hline Municípios atendidos & $\begin{array}{l}1 \text { município } \\
\text { Município onde está a cooperativa. } \\
\text { Apenas SME }\end{array}$ & $\begin{array}{l}3 \text { municípios } \\
\text { Município onde está a cooperativa: SME e escolas } \\
\text { estaduais. } \\
2 \text { municípios próximos: SME }\end{array}$ \\
\hline $\begin{array}{l}\text { Produtos comercializados/Forma } \\
\text { de comercialização }\end{array}$ & $\begin{array}{l}5 \text { produtos } \\
3 \text { in natura: alface, banana prata e } \\
\text { couve. } \\
2 \text { processados: mandioca descascada e } \\
\text { biscoito de polvilho. } \\
\text { Forma de comercialização: individual. }\end{array}$ & $\begin{array}{l}12 \text { produtos: } \\
\text { - } 10 \text { in natura: abóbora japonesa, abobrinha verde, alface, } \\
\text { banana maçã, banana prata, beterraba, cenoura, couve, } \\
\text { laranja e repolho. } \\
\text { - } 2 \text { processados: mandioca descascada e biscoito de } \\
\text { polvilho. } \\
\text { Forma de comercialização: via cooperativa }\end{array}$ \\
\hline $\begin{array}{l}\text { Número de agricultores familiares } \\
\text { envolvidos }\end{array}$ & 4 & 10 \\
\hline \multicolumn{3}{|l|}{ ser } \\
\hline Municípios atendidos & Inexistente & 3 municípios \\
\hline Número de entidades atendidas & Inexistente & $\begin{array}{l}24 \text { entidades: } \\
-18 \text { de assistência social e } 6 \text { escolas públicas }\end{array}$ \\
\hline $\begin{array}{l}\text { Número de agricultores familiares } \\
\text { envolvidos }\end{array}$ & Inexistente & 30 agricultores \\
\hline Produtos comercializados & Inexistente & $\begin{array}{l}29 \text { produtos: } \\
-20 \text { in natura: abóbora japonesa, abobrinha verde, alface, } \\
\text { banana maçã, banana prata, beterraba, cenoura, cheiro } \\
\text { verde, frango vivo, guariroba, jiló, mamão formosa, } \\
\text { mandioca, maracujá, mexerica, milho, ovos, quiabo, } \\
\text { rabanete e rúcula. } \\
\text { - } 9 \text { processados: biscoito de queijo, bolo de mandioca, } \\
\text { carne bovina, doce de coco, doce de laranja, farinha de } \\
\text { mandioca, pão, polvilho e rosca. }\end{array}$ \\
\hline Valor do projeto & Inexistente & $\mathrm{R} \$ 169.975,75$ \\
\hline Total produtos $(\mathrm{kg})$ & Inexistente & $48.016 \mathrm{~kg}$ \\
\hline$\%$ de mulheres & Inexistente & $53,3 \%(n=16)$ \\
\hline \multicolumn{3}{|c|}{ COOPERATIVA } \\
\hline Número de cooperados & $\begin{array}{l}21 \text { cooperados } \\
\text { (6 agricultores familiares) }\end{array}$ & $\begin{array}{l}58 \text { cooperados } \\
\text { (58 agricultores familiares) } \\
\text { Cooperados que não eram agricultores familiares saíram } \\
\text { da cooperativa }\end{array}$ \\
\hline $\begin{array}{l}\text { Vínculos institucionais } \\
\text { territoriais dos cooperados }\end{array}$ & $\begin{array}{l}2 \text { assentamentos rurais } \\
1 \text { comunidade rural } \\
\text { Emater }\end{array}$ & $\begin{array}{l}4 \text { assentamentos rurais } \\
1 \text { comunidade rural }\end{array}$ \\
\hline DAP jurídica & Não possuía & Documento emitido \\
\hline
\end{tabular}

Ao longo da execução do projeto foram também identificadas e estabelecidas parceiras visando o alcance dos objetivos e apoio às ações da cooperativa. Dentre estes parceiros citam-se: escritório regional da Agência Goiana de Assistência Técnica e Extensão Rural (Emater Goiás), Conselho Municipal de Alimentação Escolar (CMAE), Sub-Secretaria Estadual de Educação - Regional, Colegiado do Território da Cidadania do Vale do Rio Vermelho, Comissão Pastoral da Terra, Departamento de Alimentos da Vigilância Sanitária Estadual, outras cooperativas, etc.
Não foi objeto deste estudo, mas cabe ainda destacar o quanto esta experiência possibilitou aprendizagens para a equipe de estudantes e professores vinculados à UFG, assim como aos extensionistas envolvidos. O desafio posto a cada ação executada remetia a necessidade de reorientar as formações profissionais tornando-as mais próximas à realidade local, as formas de ensino e aprendizagem que estimulem à escuta ativa, o convívio com o outro e a abertura ao diálogo. 
Desenvolvimento humano e mercados locais. Alexandre, Martins e Harold

\section{CONCLUSÕES}

Procuramos demonstrar neste artigo como o fortalecimento de uma cooperativa de AF pode contribuir para o acesso a mercados locais, incluindo os chamados mercados institucionais e potencializar a atuação articulada de AF visando a superação de desafios e a promoção do capital social.

Reconhece-se que esta avaliação apresenta limitações quanto a análise de sua efetividade, por não ter medido os impactos econômicos, sociais e na qualidade de vida dos participantes desta ação de intervenção. Recomenda-se a continuidade deste estudo e apontam-se questões que merecem melhor aprofundamento, como: em que medida a atuação intersetorial envolvendo a universidade, entidades de $\mathrm{AF}$, órgãos municipais e estaduais contribuíram para a sustentabilidade desta ação? Quais foram os impactos sociais, econômicos e na qualidade de vida sobre a vida das famílias participantes? Em que medida as ações e processos realizados impactaram na forma como os membros da cooperativa continuaram a agir e conduzir as atividades com os cooperados?

Os dados apresentados indicam o potencial que a cooperação intersetorial e interprofissional pode ter em promover o desenvolvimento rural sustentável, principalmente quando associado a cooperativas locais.

\section{AGRADECIMENTOS}

A todos os(as) agricultores(as) familiares participantes. Ao edital Proext 2013 que possibilitou acesso a recursos financeiros para pagamento de despesas do projeto e apoio a estudantes bolsistas. Ao Prof. Gabriel Medina - UFG, pelo apoio nas atividades de campo.

\section{REFERÊNCIAS}

[1] United Nations Organization. Transforming our world: The 2030 agenda for sustainable development. New York: United Nations Organization; 2015.

[2] Landorf H, Doscher S, Rocco T. Education for sustainable human development towards a definition. Theory and Research in Education. 2008;6(2):221-236.

[3] Sen A. O desenvolvimento como expansão de capacidades. Lua Nova.1993;28/29:313-334.
[4] Sen A. Desenvolvimento como liberdade. São Paulo: Cia. das Letras; 2000.

[5] Sachs JD. From Millennium Development Goals to Sustainable Development Goals. The Lancet. 2012;379:22062211.

[6] Triches RM, Schneider S. Alimentação, sistema agroalimentar e os consumidores: novas conexões para o desenvolvimento rural. Cuadernos de Desarrollo Rural. 2015;i2(75):1-20.

[7] Jones A. Healthy food for a healthy world: leveraging agriculture and food to improve global nutrition. A report issued by an independent advisory group. Chicago: The Chicago Council on Global Affairs; 2015.

[8] Sundaram JK, Rawal V, Clark MT. Ending Malnutrition from commitment to action. Itália/Índia: FAO/Tulika Books; 2015.

[9] Freitas TD, Rambo AG, Schneider S. Desenvolvimento humano e bem-estar no meio rural como superação da vulnerabilidade: o caso de Arroio do Tigre/RS. Colóquio Revista do Desenvolvimento Regional. 2014;11(2):9-30.

[10] Schneider S, Shiki S, Belik W. Rural development in Brazil: overcoming inequalities and building new markets. Revista Economia Agraria. 2010;LXV(2):225-259.

[11] Schmitt C. Aquisição de alimentos da agricultura familiar. Integração entre política agrícola e segurança alimentar e nutricional. Revista de Política Agrícola. 2005;XIV(2):78-88.

[12] Rocha C, Burlandy L, Maluf R. Small Farms and Sustainable Rural Development for Food Security: The Brazilian Experience. Development Southern Africa. 2012;29(4):519-529.

[13] Sidaner E, Balaban D, Burlandy L. The Brazilian school feeding programme: an example of an integrated programme in support of food and nutrition security. Public Health Nutrition. 2013;16(6):989-994.

[14] Schneider S. Family farming in Latin America and the Caribbean: looking for new paths. of rural development and food security. International Policy Centre for Inclusive Growth (IPCIG) Working Paper; 2016:137.

[15] Brasil. Fundo Nacional de Desenvolvimento da Educação. Lei no 11.947, de 16 de junho de 2009. Dispõe sobre o atendimento da alimentação escolar e do Programa Dinheiro Direto na Escola aos alunos da educação básica. Diário Oficial da União. 16 jun 2009.

[16] Bezerra OMPA, Bonomo E, Silva CAM, Correa MS, Souza $\mathrm{AA}$, et al. Promoção da aquisição de produtos da agricultura familiar para a alimentação escolar em Territórios da Cidadania de Minas Gerais e Espírito Santo. Rev. Nutr. 2013;26(3):335-342. 
Desenvolvimento humano e mercados locais. Alexandre, Martins e Harold

[17] Triches RM, Schneider S. Alimentação escolar e agricultura familiar: reconectando o consumo à produção. Saúde e Sociedade. 2010;19(4):933-945.

[18] Paula MM, Kamimura QP, Silva JLG. Mercados institucionais na agricultura familiar: Dificuldades e desafios. Revista de Política Agrícola. 2014;1:33-43.

[19] Alexandre VP, Gomes LOF, Silva SU, Almeida GM, Martins $\mathrm{KA}$, et al. Do campo à escola: compra de alimentos da agricultura familiar pelo Programa Nacional de Alimentação Escolar em Territórios da Cidadania de Goiás. Segur. Aliment. Nutr. 2016;23:1049-1064.

[20] Medina G, Camargo R, Silvestre W, Lee F. Retrato da Agricultura Familiar em Goiás. In: Medina G. Agricultura Familiar em Goiás: lições para o assessoramento técnico. Goiânia: Editora Kelps; 2012. p. 17-44.

[21] Brasil. Conselho Federal de Nutricionistas. Resolução/CFN no 465, de 23 de agosto de 2010. Dispõe sobre as atribuições do Nutricionista, estabelece parâmetros numéricos mínimos de referência no âmbito do Programa de Alimentação Escolar (PAE) e dá outras providências. Diário Oficial da União. 25 ago 2010.

[22] Alexandre VP. Construindo novas trajetórias e fortalecendo redes por meio de desenvolvimento rural sustentável - FANUT 133. Goiânia: Projeto cadastrado na Pro Reitoria de Extensão e Cultura (PROEC UFG); 2012.

[23] Instituto Brasileiro de Geografia e Estatística - IBGE. Cidades [internet]. 2014. [acesso em 17 nov 2017]. Disponível em: http://www.ibge.gov.br

[24] Brasil. Ministério do Desenvolvimento Agrário (MDA). Emissão de extrato de DAP por município [internet]. 2013. [acesso em 24 jun 2017]. Disponível em: http//www.mda.gov.br

[25] Patton MQ. Qualitative evaluation and research methods. 2. ed. California: Sage; 2007.

[26] Creswell JW, Clark VLP. Designing and conducting mixed methods research. 2. ed. California: Sage; 2011.

[27] Helsloot N, Hak T. Pêcheux's Contribution to Discourse Analysis. Forum Qualitative Social Research. 2016;8:2.

[28] Vogt SPC, Souza RS. Mercados institucionais como instrumento de fortalecimento da agricultura familiar: uma análise do Programa de Aquisição de Alimentos na Região Celeiro - RS. In: Livro de Resumos do Congresso da Sociedade Brasileira de Economia, Administração e Sociologia Rural; v. 47; 2009; Porto Alegre: SOBER; 2009.

[29] Teodoro PHM. O paradigma do desenvolvimento e a polissemia da sustentabilidade. Revista Sustentabilidades. 2011;118.
[30] Brasil. Ministério da Saúde. Secretaria de Atenção à Saúde. Departamento de Atenção Básica. Guia alimentar para a população brasileira. 2. ed. Brasília: Ministério da Saúde; 2014.

[31] Pan American Health Organization. World Health Organization. Ultra-processed food and drink products in Latin America: Trends, impact on obesity, policy implications. Washington, DC: PAHO; 2015.

[32] Brasil. Fundo Nacional de Desenvolvimento da Educação. Resolução no 26, de 17 de junho de 2013. Dispõe sobre o atendimento da alimentação escolar aos alunos da educação básica no âmbito do Programa Nacional de Alimentação Escolar - PNAE. Diário Oficial da União. 17 jun 2013.

[33] Alexandre VP, Pereira M, Medina G, Martins BB. Passos da comercialização pelo Programa Nacional de Alimentação Escolar (PNAE) e pelo Programa de Aquisição de Alimentos (PAA). In: Medina G. Agricultura Familiar em Goiás: lições para o assessoramento técnico. Goiânia: UFG; 2014. p. 23-54.

[34] Cazella AA, Bonnal P, Maluf RS. Multifuncionalidade da agricultura familiar no Brasil e o enfoque da pesquisa. In: Cazella AA, Bonnal P, Maluf RS. Agricultura familiar: multifuncionalidade e desenvolvimento territorial no Brasil. Rio de Janeiro: Mauad X; 2009.

[35] Teo CRPA, Monteiro CA. Marco legal do Programa Nacional de Alimentação Escolar: uma releitura para alinhar propósitos e prática na aquisição de alimentos. Rev. Nutr. 2012;25(5):657-668.

[36] Peixinho AML. A trajetória do Programa Nacional de Alimentação Escolar no período de 2003-2010: relato do gestor nacional. Ciênc. Saúde Coletiva. 2013;18(4):909-916.

[37] Brasil. Conselho Nacional de Segurança Alimentar e Nutricional. Documento de referência: Comida de verdade no campo e na cidade. 5a Conferência Nacional de Segurança Alimentar e Nutricional. Brasília(DF): Consea; 2015.

[38] Paiva CS, Camargo IBC, Correia MHS. Análise dos Cardápios da Alimentação Escolar Pública de Município Goiano de Pequeno Porte. [Trabalho de Conclusão de Curso]. Goiânia: Universidade Federal de Goiás; 2014. 